\title{
Development and Validation of a Dynamic Model for Flotation Predictive Control Incorporating Froth Physics ${ }^{\dagger}$
}

\author{
Paulina Quintanilla * $\mathbb{D}$, Stephen J. Neethling and Pablo R. Brito-Parada \\ Department of Earth Science and Engineering, Imperial College London, London SW7 2AZ, UK; \\ s.neethling@imperial.ac.uk (S.J.N.); p.brito-parada@imperial.ac.uk (P.R.B.-P.) \\ * Correspondence: p.quintanilla18@imperial.ac.uk \\ + Presented at International Conference on Raw Materials and Circular Economy, Athens, Greece, \\ 5-9 September 2021.
}

Keywords: froth flotation; flotation modelling; flotation control; model calibration; model validation; model predictive control

check for updates

Citation: Quintanilla, P.; Neethling, S.J.; Brito-Parada, P.R. Development and Validation of a Dynamic Model for Flotation Predictive Control Incorporating Froth Physics. Mater. Proc. 2021, 5, 13. https://doi.org/ 10.3390/materproc2021005013

Academic Editor:

Konstantinos Simeonidis

Published: 9 November 2021

Publisher's Note: MDPI stays neutral with regard to jurisdictional claims in published maps and institutional affiliations.

Copyright: (c) 2021 by the authors. Licensee MDPI, Basel, Switzerland. This article is an open access article distributed under the terms and conditions of the Creative Commons Attribution (CC BY) license (https:// creativecommons.org/licenses/by/ $4.0 /)$.
In mining, froth flotation is the largest tonnage separation process used to separate valuable minerals from waste rock. The froth flotation process is carried out in stirred tanks in which chemical reagents and air are added. Reagents make the valuable mineral particles hydrophobic, so they repel water. As a consequence, the valuable mineral particles attach to air bubbles, covering them and generating bubble-particle aggregates. The bubble-particle aggregates rise to the top of the tank, forming a froth that overflows as a mineral-rich concentrate. The waste rock particles do not attach to the bubbles and leave from the bottom of the tank.

As froth flotation is a large-scale process, even small improvements in the separation efficiency would translate into important increments in production [1,2]. Optimising the process to increase metal recovery also increases the sustainability of the operation. One of the most efficient ways to optimise the process is to implement advanced control techniques [3]. Model predictive control (MPC), in particular, is widely considered as one of the most efficient strategies to optimise a multivariable process, using an explicit, dynamic model of the process to predict the future behaviour of the most important variables [4]. However, implementing MPC for froth flotation is very challenging, as modelling this process is a difficult task due to the very complex dynamics involved and since it is a multiphase (gas-liquid-solid) system with inherent instability [2,3,5-8]. While complex models to describe the phenomena of the flotation process can be found in the literature, models for control purposes must be simple enough-yet robust - to solve the control problem in real time. Both characteristics conflict with each other; thus, it is necessary to find a trade-off between simplicity and robustness.

In this study, we propose a novel dynamic flotation model for MPC purposes. The full model development can be found in [9]. Our model differs from the others found in previous studies since, for the first time, the physics of the froth phase is included for control. The importance of including froth physics lies in the fact that the phenomena occurring in the froth - such as air recovery, bubble coalescence, and bubble burstingultimately determine the separation efficiency and thus the recovery of minerals [10]. The model proposed can be classified as a differential and algebraic equation (DAE) problem, which has $31+12 i+5 k$ equations, where $i$ is the number of mineralogical classes, and $k$ is the number of bubble size classes in the pulp phase. An analysis of degrees of freedom for control revealed that two variables need to be fixed to have a completely determined model. Since the model is quite extensive, here, we only discuss some of the equations used to model each of the phases of a flotation system.

Experiments were carried out in an $87 \mathrm{~L}$ laboratory flotation tank at Imperial College London in order to calibrate and validate the model. All experiments were performed in a 
three-phase system (solid-liquid-gas). The solids system consisted of silica with an average particle size of $75 \mu \mathrm{m}$. In the experiments, we measured important flotation variables, such as pulp level (dynamic), air recovery (dynamic), and pulp bubble size distribution (steady state) while fixing the two degrees of freedom: air and tailings flowrates (through their respective control valves). These flowrates are the typical manipulated variables in flotation control. Three values of air flowrates and tailings flowrates were fixed during the experiments, having a total of nine different operating conditions. The experiments in each operating condition were carried out in triplicate for further statistical analysis.

The experimental data obtained were used to calibrate and validate the proposed model, as shown in [11]. In the pulp phase, one of the most important variables for flotation control is the pulp level. Results for the validation of the dynamic model for pulp level prediction, based on the model proposed by [12], revealed high accuracy in terms of the prediction and trends for this variable. In the froth phase, air recovery plays a crucial role, as it is strongly linked to froth stability and, in turn, with the overall flotation performance. However, little work has been conducted in terms of including this variable in control strategies. Therefore, one of our main aims was to include this variable in the model in order to obtain a complete flotation model capable of capturing the effect of changes in froth stability. The experimental data analysed here are in exceptionally good agreement with the model predictions. The standard error of estimate calculated for air recovery suggested that the average difference between the observed values and the model prediction will fall within the range from $1.29 \%$ to $6.77 \%$, depending on the operating condition. What is even more important here, though, is that the model can follow the trends in air recovery. This ability is crucial for the implementation of our model into predictive control strategies for enhanced metallurgical performance.

In summary, we validated a new dynamic flotation model, which is suitable for MPC strategies and incorporates froth physics. Having models of the froth phase for MPC will allow detailed predictions and, therefore, better control strategies to maximise the amount of valuable metal recovered. This enhancement in the recovery of valuable metals will help in taking a step towards better utilisation of the resources, contributing to the sustainability of the process.

Data Availability Statement: The data that support the findings of this study are available from the corresponding author, P.Q, upon reasonable request.

Acknowledgments: Paulina Quintanilla would like to acknowledge the National Agency for Research and Development (ANID) for funding this research with a scholarship from "Becas Chile". The Society of Chemical Industry is also greatly acknowledged for the support granted by the SCI Messel Scholarship 2020.

Conflicts of Interest: The authors declare no conflict of interest.

\section{References}

1. Ferreira, J.; Loveday, B. An improved model for simulation of flotation circuits. Miner. Eng. 2000, 13, 1441-1453. [CrossRef]

2. Quintanilla, P.; Neethling, S.J.; Brito-Parada, P.R. Modelling for froth flotation control: A review. Miner. Eng. 2020, $162,106718$. [CrossRef]

3. Bergh, L.; Yianatos, J. The long way toward multivariate predictive control of flotation processes. J. Process. Control. 2011, 21, 226-234. [CrossRef]

4. Camacho, E.F.; Bordons, C. Model Predictive Control; Springer: London, UK, 2007. [CrossRef]

5. Desbiens, A.; Hodouin, D.; Najim, K.; Flament, F. Long-range predictive control of a rougher flotation unit. Miner. Eng. 1994, 7, 21-37. [CrossRef]

6. Desbiens, A.; Hodouin, D.; Mailloux, M. Nonlinear Predictive Control of a Rougher Flotation Unit Using Local Models. IFAC Proc. Vol. 1998, 31, 287-292. [CrossRef]

7. Sbarbaro, D.; del Villar, R. Advanced control and supervision for mineral processing. In Advances in Industrial Control; Springer: Berlin/Heidelberg, Germany, 2010. [CrossRef]

8. Shean, B.; Cilliers, J. A review of froth flotation control. Int. J. Miner. Process. 2011, 100, 57-71. [CrossRef]

9. Quintanilla, P.; Neethling, S.J.; Navia, D.; Brito-Parada, P.R. A dynamic flotation model for predictive control incorporating froth physics. Part I: Model development. Miner. Eng. 2021, 173, 107192. [CrossRef] 
10. Neethling, S.; Brito-Parada, P. Predicting flotation behaviour-The interaction between froth stability and performance. Miner. Eng. 2018, 120, 60-65. [CrossRef]

11. Quintanilla, P.; Neethling, S.J.; Navia, D.; Brito-Parada, P.R. A dynamic flotation model for predictive control incorporating froth physics. Part II: Model calibration and validation. Miner. Eng. 2021, 173, 107190. [CrossRef]

12. Shean, B.; Hadler, K.; Neethling, S.; Cilliers, J. A dynamic model for level prediction in aerated tanks. Miner. Eng. 2018, 125, 140-149. [CrossRef] 